\title{
A STUDY OF HIGH LIFT AERODYNAMIC DEVICES ON COMMERCIAL AIRCRAFTS
}

\author{
Swamy Naidu Venkata NEIGAPULA (1D 1, Satya Prasad MADDULA (1D2 ${ }^{2}$, Vasishta Bhargava NUKALA (1D) 3, \\ ${ }^{1}$ Department of Mechanical Engineering, National Institute of Technology, Raipur, India \\ ${ }^{2}$ Department of Aerospace Engineering, GITAM University, Hyderabad, India \\ ${ }^{3}$ Department of Mechanical Engineering, Sreyas Institute of Engineering and Technology, Nagole, Hyderabad, India
}

Received 08 March 2019; accepted 18 May 2020

\begin{abstract}
Aerodynamic performance of aircraft wings vary with flight path conditions and depend on efficiency of high lift systems. In this work, a study on high lift devices and mechanisms that aim to increase maximum lift coefficient and reduce drag on commercial aircraft wings is discussed. Typically, such extensions are provided to main airfoil along span wise direction of wing and can increase lift coefficient by more than $100 \%$ during operation. Increasing the no of trailing edge flaps in chord wise direction could result in $100 \%$ increment in lift coefficient at a given angle of attack but leading edge slats improve lift by delaying the flow separation near stall angle of attack. Different combinations of trailing edge flaps used by Airbus, Boeing and McDonnel Douglas manufacturers are explained along with kinematic mechanisms to deploy them. The surface pressure distribution for $30 \mathrm{P} 30 \mathrm{~N}$ airfoil is evaluated using $2 \mathrm{D}$ vortex panel method and effects of chord wise boundary layer flow transitions on aerodynamic lift generation is discussed. The results showed better agreements with experiment data for high Reynolds number ( 9 million) flow conditions near stall angle of attack.
\end{abstract}

Keywords: flap, slat, aircraft wing, high lift, aerofoil, drag, pressure.

\section{Introduction}

Slats and flaps are high lift devices, intended to produce maximum lift coefficients on aerodynamically designed surfaces as found on aircraft wings, helicopter blades. The use of aerodynamic extensions are done in order to increase the effective plan form area of wing thereby generating extra lift force required for an aircraft wing. An aircraft wing is subjected to varying flow conditions during take-off or landing as well as cruise modes. Typically, the flow field surrounding many of the aircraft wing structures is highly non-linear and unsteady in nature. The unsteady flow nature on wing can be analyzed by computational methods accurately (Reckzeh, 2004; Sankar et al., 2001; Catalano et al., 2012). It is known that CFD based methods such as URANS, large eddy simulation, direct numerical simulation produce highly accurate results but are computationally intensive for predicting flows at high Reynolds number and for complex geometries. In contrast, other computational methods such as basic panel methods by Hess and Smith (1967) are suitable to analyze potential and incompressible flows over multi element airfoils. The aerodynamic performance of an airfoil includes lift, drag and moment coefficients. The use of multi-element airfoils, for example $30 \mathrm{P} 30 \mathrm{~N}$ as found on commercial aircraft wings has been a good subject of case study by several researchers in the past for analyzing aerodynamic performance under different flow configurations (Reckzeh, 2004; Sankar et al., 2001; Catalano et al., 2012; Lockhard \& Choudhari, 2009). The research methods included various tests in wind tunnel experiments, for instance the effect on aerodynamic performance of aircraft wing by varying the wall or ground distance to the wing surface (Xuguo et al., 2009; Lockhard \& Choudhari, 2010). In addition to aerodynamic performance, aero-acoustic studies have been done by several researchers in the past decade (Pascioni et al., 2014; Lockhard \& Choudhari, 2010; Jawahar et al., 2017). Studies revealed that flow induced noise from slats and flaps could be reduced through boundary layer control and involve blowing and suction procedures. These methods control the boundary layer thickness while reducing pressure drag on inboard and outboard sections of wing. Even though most high lift devices such as trailing edge flaps are intended to increase the maximum lift coefficient for a modern aircraft they also introduce additional

*Corresponding author. E-mail: vasishtab@gmail.com 
drag known as interference drag and tend to offset the benefits. So, fairings are used to streamline the flow and can minimize the form or interference drag. Trailing edge flaps are mounted on aircraft wing using kinematic mechanisms that can be deployed during landing, takeoff conditions. The role of kinematic mechanisms is dealt in section 2.2 which explains the functioning of mechanisms common to commercial aircrafts. The leading edge and trailing edge flaps on high lift systems are mounted using fairings (Zaccai et al., 2016).

Heap and Crowther (2011) studied the various configurations of such high lift devices on aircraft wings that are available on commercial airliners such as Boeing, Airbus, McDonnell-Douglas (now Boeing). Tradeoff studies were conducted for various wing configurations by manufacturers in aviation industry and factors affecting flight performance for commercial aircrafts are studied. In a study by Husse (2006) several conditions were considered to investigate the fuel consumption by aircrafts during its operation, lift-off and landing scenarios. Furthermore, computational study by Xuguo et al. (2009), Deng et al. (2018) has shown the effects of ground height distance to airfoil on the lift, drag and nose up or nose down pitching moments of an aircraft for two different airfoil configurations. Firstly by varying the ground distance height for clean airfoil under different flow condition using the lift drag and moment coefficients. Secondly for a high lift configuration, a multi element airfoil, 30P30N was considered for similar distance to ground height case. It was found that for high lift configurations, lift, drag and nose down pitching moments have decreased. However, in the former case, lift and nose down pitching moment increased up to a certain value, while induced drag was found to decrease. The investigated parameter was measured in terms of ratio of ground distance height and chord length of airfoil configuration and its effect on surface pressure distribution was also dealt for such conditions. The ground effect was combined with boundary layer flow transitions on airfoils to analyze confluent boundary layer flow characteristics between the flap gap and main element. The presence of vortices formation for confluent flows at varying angles of attack also confirmed the airfoil experienced higher lift coefficient for different Reynolds numbers. Studies from Zhang et al. (2017), Jain et al. (2015) have shown that effect of Gurney flaps on NACA 0012 airfoil attached at $\sim 1.5 \%$ c distance from trailing edge increases maximum lift coefficient by $2 \%$ but at the expense of increased profile drag. The use of Gurney flaps was first investigated by Liebeck (1978) using inverse design approach to determine high lift on airfoils. The influence on the maximum lift coefficient on the wing due to addition of Gurney flaps known as tabs in the flap cove region has shown to increase in lift coefficient and nose down pitching moment coefficient for multi-element airfoil due to downward action of force along chord.

This paper is confined to following sections of study. In first section, the primary significance and objective of high lift devices on aircraft wings presents a discussion about lift improvement methodologies through use of slots on leading and trailing edge regions of airfoil. The techniques available to improve lift coefficient are described and the importance of such devices in aircraft wings as well as the benefits pertaining to aircraft industry. In second section, maximum lift coefficients achieved for different types of high lift configurations on commercial aircraft wings are discussed as well as role of the kinematic mechanisms. In third section, steady state surface pressure coefficient has been evaluated for 30P-30N multi-element airfoil using $2 \mathrm{D}$ vortex panel method and validated with CFD results of Dong and Zhang (2012) and experiment results of Anderson et al. (1995) at $16^{\circ}$ angle of attack, Mach-0.2, Re-9 million. Finally conclusions and an overview of the future work is presented.

\section{Significance of high lift devices}

High lift devices are sophisticated equipment found on commercial aircrafts that are not only designed to produce increased lift but also to improve the flight performance. A typical passenger aircraft has three stages in a flight, takeoff, cruise and landing during which the high lift devices are deployed and retracted when required. Their position can be located either at leading edge as well as trailing edge of an aircraft's main wing. From Figure 1(a) a plain or slotted flap is flexible element attached to lower surface of trailing edge and deployed at $20^{\circ}$. A split flap or a spoiler is located aft of main wing and intended to act as aerodynamic brake by stalling the flow and creating high pressure drag. A zap flap is similar to a split flap but operates using a hinge and fairing in kinematic mechanism at the cove region. The most frequently used leading edge flap in aircraft is Kruger flap or a three-position slat that forms a unique combination with main element. As it is operated by a complex kinematic mechanism, the deployment of such flaps can be done very precisely in order to increase the maximum lift coefficient during takeoff or landing. Increasing slots either at leading or trailing edge of wing will improve the maximum lift coefficient by an order of two or three times higher compared with clean configuration of wing. This allows the increase of payload or takeoff weight of aircraft at a given angle of attack for a flight Mach number. It would also help to control the dynamic stability of aircraft during low altitude maneuver such as during landing (Reckzeh, 2004) The position of slots is critical to increase maximum lift coefficient. Figure 1(b) shows the arrangement of high lift devices on the main wing during take-off and landing stages. Figure 1(c) depicts the leading-edge profile of a real wing mounted with slat and uses a fairing for deployment. Figure 1(d) illustrates the trailing edge flap devices of a Boeing 747-400 deployed during landing. Typically arrangement of high lift devices along span wise direction is near inboard as well as outboard regions of wing.

Figure 2 depicts the innovation cycle and state of art in aircraft wing design. It can be noted that the evolution of wing design is dependent on the innovative materials 
as well as kinematic mechanisms to enhance overall flight performance. The generation of lift on an aircraft wing is caused as result of pressure gradient between suction and pressure surfaces of wing. The amount of lift produced varies with geometry and structural parameters of airfoil viz. leading-edge radius, trailing edge angle, camber, thickness to chord ratio. The deployment of trailing edge flap and slat is done for the takeoff stage partially as velocity

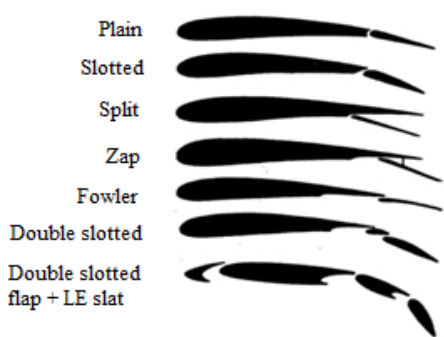

(a)

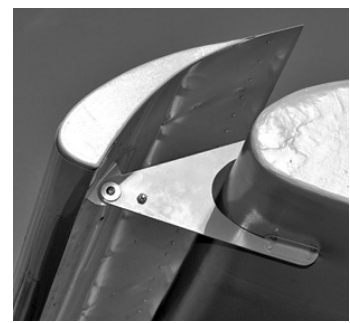

(c)

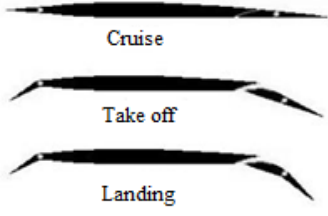

(b)

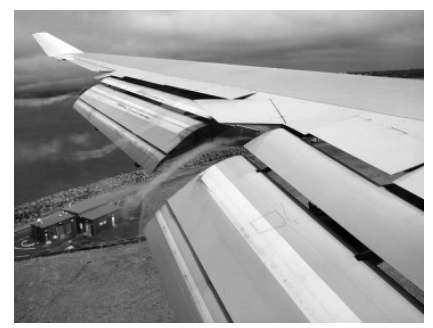

(d)
Figure 1. Position of high lift devices (a) Different types of flap and slat configurations on aircraft wing (IATA, 2019)

(b) Position of flap and slap devices during aircraft operation modes (Haroon, 2011) (c) Ventilated and fixed leading edge slat (d) Slotted flaps of Boeing 747-400 during landing of aircraft is low and thus a high lift and low drag action is produced. This helps to increase the pay load capacity or take-off weight of an aircraft. For smooth landing conditions the aircraft must again slow before the touch down on runway for which the trailing edge flap devices are deployed to produce high lift and high drag on wing surface as shown in Figure 1(b) (Husse, 2006) A leading edge slat combined with double slotted flap produces a $\mathrm{C}_{\text {Lmax }}$ of $\sim 4$ by increasing the effective camber and wing area. The increase in camber is best achieved by a slat near leading edge as shown in Figure 1(c). This affects the maximum $\mathrm{C}_{\mathrm{L}}$ during take-off or landing requirements of aircraft and subsequently the fuel efficiency.

One of the major objectives of high lift devices in aircraft design is to minimise drag at high speeds since drag becomes critical factor when components are not streamlined which result in early flow separation on surfaces. Therefore, the components are designed in streamlined manner to which the air flow can remain attached all the way back to a trailing edge of the wings. The design process is similar for tail surfaces and a sharp closure at the tail of the body contributes to dramatic increase in parasitic drag at high speeds. Also, the air flowing over the bluff bodies like cylinder would leave a wake full of swirls and contribute to a large amount of pressure drag. A higher pressure drag produced by the shape of the aircraft is kept to a minimum by streamlining, ensuring the flow to remain attached on surface. Streamlining reduces the boundary layer thickness and pressure drag. However, the aerodynamic improvement in the design of the wing itself involves a balance among conflicting factors (Chernyshev et al., 2019).

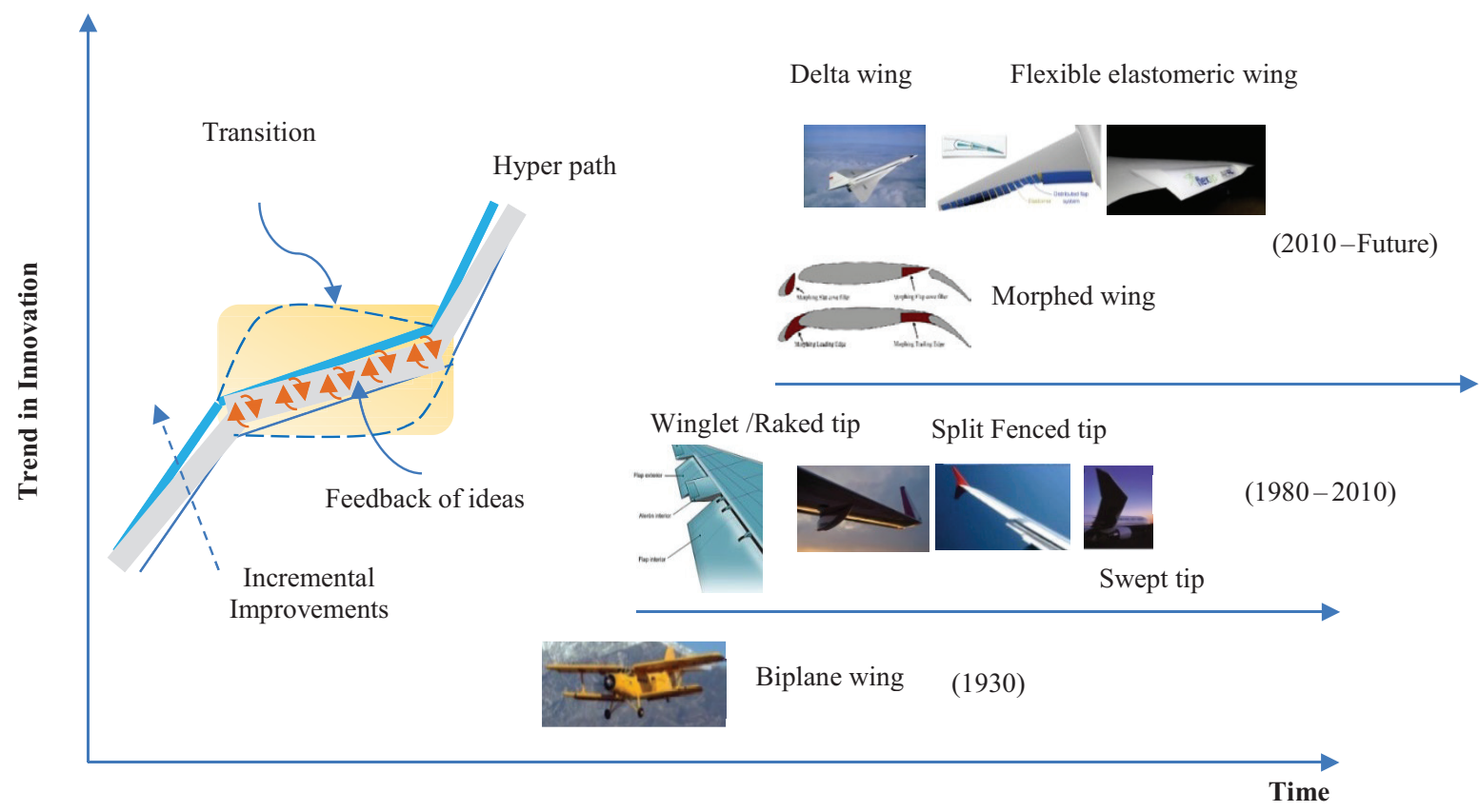

Figure 2. A roadmap of innovation cycle compared to evolution of aircraft wing innovations (adapted from Husse, 2006) 
The aspect ratio and thickness to chord ratio of aerofoil are important design variables in aircraft wing design. When the wing span is increased it reduces friction drag but increases the weight of wing. Increasing wing thickness reduces structural weight because thinner skins can be used, but increases drag, especially at the high speeds of cruising flight. On the other hand, low aspect ratio increases wing area and makes it possible to take-off and land at lower speeds and requires shorter runways however it usually results in increase of skin-friction drag at high speeds for the rest of the flight.

Improvements in aerofoil design are focused particularly at the high-speed phase of flight. Such improvements have made it possible to find more favourable balance between span, thickness, area, and weight. The tip of a wing is critical in design of an aircraft. Adding winglets tilted upward at the tips, either to new aircraft or as retrofits to existing models, has seen 3-5\% reductions in fuel burn, depending on the length of the flight and type of aircraft. Winglets also reduce induced drag without needing a significant increase in horizontal span. Although winglets are beneficial during long range flight operations, the presence of winglets would be an issue for parking at some airport gates, for increase in wingspan. An alternative to the winglet is the raked tip as which produces similar drag reduction for long-range aircraft, providing a lightweight wingtip design.

From Figure 3(a) slat contribution to lift augmentation at a given angle of attack is significant and increases the maximum $\mathrm{C}_{\mathrm{L}}$ or $\mathrm{L} / \mathrm{D}$ ratio by $80-100 \%$. Presence of leading edge slat delays the boundary layer flow separa-

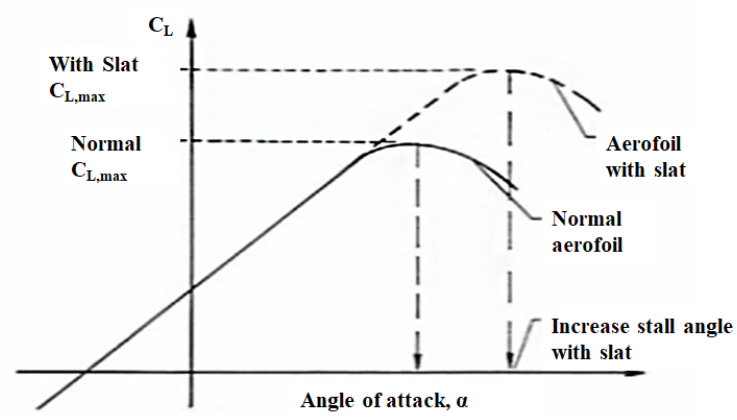

(a)

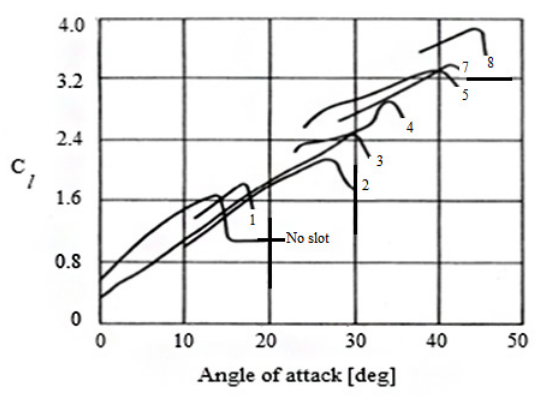

(c) tion and prevents dynamic stall over main airfoil (Heap \& Crowther, 2011). Figure 3(b) shows the sectional lift coefficient comparison for plain and slotted wings. The maximum $\mathrm{C}_{\mathrm{L}}$ of 3.2 is obtained for wing using a fowler flap with $\sim 65 \%$ improvement. In Figure 3(c) the effect of no of slots on improvement of lift coefficient is illustrated. The takeoff and landing performance of aircraft vary with acceleration distance on ground as well as stepped climb rates with a slope angles between $2^{\circ}$ and $3^{\circ}$. The thrust to weight ratio, span wise wing loading, maximum lift coefficient, pressure and friction drag are other factors which affect the take-off attitude of aircraft (Reckzeh, 2008; Heap \& Crowther, 2011). In contrast the landing performance also depends on additional parameter known as the approach angle and distance to approach. The takeoff and landing of civil aircrafts is done according to federal airworthiness regulations (FAR) part 25 (FAA, 2019). Civil aircrafts use actively controlled leading slats or Krueger flaps which can be deployed in different positions during takeoff and landing situations in order to reduce structural load on wing. Empirical studies have found that pay load capacity increase roughly an order of $1-2 \%$ with a change of $3 \%$ in maximum $\mathrm{C}_{\mathrm{L}}$ or glide ratio of a wing. The gross tonnage in Boeing series of aircraft allows 560-600 tons with a total payload up to 60 tons. According to study of Reckzeh (2004) for a twin engine jet aircraft a 5\% increase in $\mathrm{C}_{\mathrm{Lmax}}$ leads to $12-15 \%$ increase in payload, while a $5 \%$ increase in $\mathrm{L} / \mathrm{D}$ ratio increases payload by $20 \%$. Similarly a $5 \%$ increase in $\mathrm{C}_{\mathrm{Lmax}}$ during landing would increase $25 \%$ of payload. The design process of such wings involve advanced tools such as CFD flow solvers to resolve the

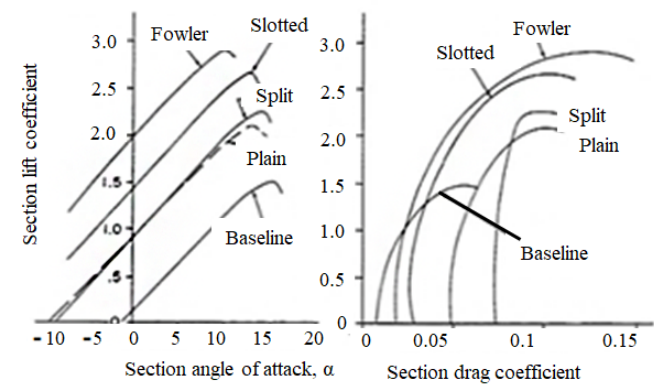

(b)

Figure 3. Illustration of the maximum lift coefficient vs angle of attack (a) airfoils with and without leading edge slat (IATA, 2019) (b) drag polar for various types of flaps with respect to baseline airfoil (IATA, 2019) (c) varying number of slots on aircraft wing (Rudolph,1996) 
complex boundary layer flow physics. For high lift systems, the takeoff and landing performances are dependent upon the acceleration distance on ground, climb rates, approach angle and deceleration distance on ground. In case of takeoff performance, the aircraft climb rate can be found using Eq. (1)

$$
\phi=\frac{T}{W}-\frac{1}{L / D}
$$

where, $T$ is the total thrust force, $W$ is the total weight of aircraft, $L$ - total lift produced by wing, $D$ - total drag on aircraft. The acceleration distance on ground is expressed by Eq. (2)

$$
s_{a}=f\left(\frac{W}{S}, \frac{L}{D}, C_{L \max }, C_{D}, \mu\right) .
$$

On the other hand, for the landing performance of an aircraft, the approach angle is limited to $3^{\circ}$ according to FAR rules. It is expressed in terms of wing loading and glide ratio and given by Eq. (3)

$$
\varphi=f\left(\frac{W}{S}, \frac{L}{D}, C_{L \max }\right) .
$$

The deceleration distance on ground for an aircraft is given by Eq. (4)

$$
s_{d}=f\left(\frac{W}{S}, C_{L \max }, C_{D}, \mu, T R\right) .
$$

The climb rate for landing is also function of thrust to weight ratio and glide ratio and given by Eq. (5)

$$
\phi=f\left(\frac{T}{W}, \frac{L}{D}\right),
$$

where, $S$ - wing span area, $C_{L \max }$ is maximum lift coefficient, $\mu$ is the friction coefficient during ground roll, TR is the reverse thrust force. It can be noted that no of trailing edge slots to generate maximum lift vary with aircraft manufacturer and flight range. The total drag for an aircraft wing is evaluated by Eq. (6)

$C_{D}=C_{D 0}+\Delta C_{D, \text { flap }}+\Delta C_{D, \text { slat }}+\Delta C_{D, \text { gear }}+\Delta C_{D, \text { wave }}+\frac{C_{L}^{2}}{\pi A e}$,

$e$ is Oswald efficiency factor expressed in terms of flight Mach number, wing aspect ratio, span wise airfoil thickness, wing sweep angle and number of engines on wing. Typical values for e depend on the position of flaps, slats and landing gear. The value of this factor is high when the high lift elements are in retracted state than when they are extended or deployed. $C_{D o}$ is the zero lift drag when the high lift devices are in retracted position. $\Delta C_{D \text {, flap }}$, $\Delta C_{D \text {, slat }}$, and $\Delta C_{D \text {, gear }}$ are additional drag contributing elements. $\Delta C_{D \text {, wave }}$ is drag increment due to flight Mach number. $C_{L}$ is the lift coefficient, $A$ - aspect ratio of wing.

\section{Configuration of high lift devices on commercial aircrafts}

Various combinations of lift enhancing devices on inboard and outboard sections of aircraft wing at the trailing edge are shown in Figure 4. It also shows the double slotted flaps at trailing edge for inboard and outboard sections of wing. The inboard section of wing double slotted flaps are used while for outboard station single slotted flap is utilized to produce maximum lift as found in Boeing B767 and B777. The double slotted trailing edge flaps are used in Douglas aircrafts, DC8-63/77, MD-11.

The slotted configuration contains the curvature of aft filler region near trailing edge which affects the maximum lift distribution and load carrying ability of wing. The presence of high lift elements will improve flight performance by increasing effective camber and wing area. It controls the surface pressure peaks and varies the lift force on wing but also introduces induced drag. It is unlike the viscous and wave drag produced due to boundary layer thickness, fluid viscosity and shock waves formed on wing at supersonic and transonic flight speeds. One of the important objectives to add slots on aircraft wing is to enhance maximum lift coefficient. Lift coefficient has direct impact on takeoff weight of aircraft and fuel consumption efficiency during take-off and landing.

However, it has been found that during cruise stage, control of boundary layer thickness is important strategy to reduce the pressure drag which leads to the reduction in fuel consumption by average of 5\% during such flight conditions (Heap \& Crowther, 2011). The capacity of the fuel tank is based on the position of such devices along the wingspan and volume of fuel consumed as function of thrust to weight, lift to drag ratios. As with global change in price of aviation turbine fuel seen over the last decade (IATA, 2019) any improvement in fuel consumptions of aircraft will provide huge benefits to aviation industry as well as reduction in harmful carbon emissions. It is estimated that each ton of fuel saved leads to reduction of $\sim 3-4$ tons in $\mathrm{CO}_{2}$ emissions (Husse, 2006). Also, following the perfect flight procedures reduce flight time. A $10 \mathrm{~min}$ reduction in time can save up to 4500 liters of fuel which translates to elimination of $13000 \mathrm{~kg}$ of carbon emissions. The fuel consumption for an aircraft is influenced by the structural weight and the lift produced during take-off and landing stages. During takeoff, the angle of climb (AOC), rate of climb (ROC) are critical parameters that affect the fuel consumption. According to federal aviation administration (FAA) regulations part 25 if the angle of climb or rate of climb is increased, the fuel consumption by an aircraft will also increase. The lift produced on aircraft wing will also vary with angle of incidence, position of flap and slat devices. Similarly, during descent stage, a shorter landing distance will tend to increase fuel consumption and vice-versa.

The aerodynamic efficiency of a high-lift system varies with number of flap or slat elements along with the support and actuation system. Essentially flap support systems can be divided into (i) fixed or simple hinge, (ii) track system (iii) linkage system. Fixed hinge system consists of simple flaps and allows only rotational motion about pivot point. Track and linkage systems consist of combination of flaps attached to fairing and involve a rotational motion about a pivot point and also forward traverse such as 
Position on wing span

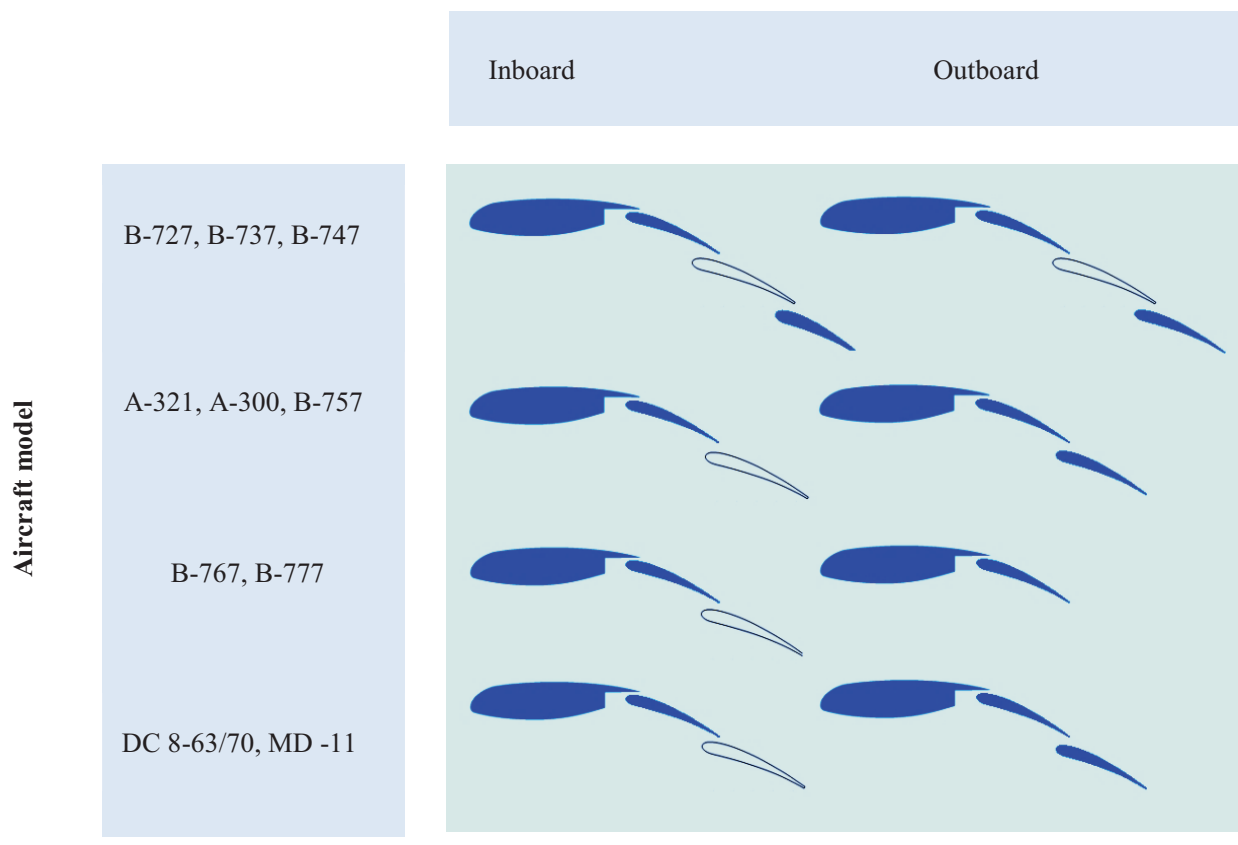

Legend: A - Airbus, B - Boeing, DC - Douglas Craft, MD - McDonnel Douglas

Figure 4. Schematic view of trailing edge flap/slat configurations used in Boeing, Airbus and McDonnel Douglas aircrafts (adapted from Heap \& Crowther, 2011; Reckzeh, 2004)

Fowler motion. In order to reduce cruise drag the drooped hinge has to be moved further up resulting in a smaller flap fairing. Kruger flaps are used on several passenger transport aircrafts due to light weight structure and simple design. However, Kruger flaps usually have only two operating modes viz. cruise and extended and as a result, take-off performance may be less efficient compared to three-position slats. An advantage of Kruger flaps over slats is that only the pressure surface of the cruise air foil is affected at the leading edge and thus resulting surface behaves like a cruise wing. It can be noted that due to lack of surface discontinuities on the suction surface of Kruger flap, it is a popular option for laminar flow wing designs. Aircraft wing design in terms of the leading edge devices viz slats, Kruger flaps combined with single-and double-slotted Fowler flaps at trailing edge are predominant high-lift devices of choice. But problem remains in terms of complex mechanisms to actuate these extensions. The role of kinematic mechanisms in high lift systems is further illustrated in section 2.2.

From Figure 5(a) the leading-edge slat takes three positions for take-off, landing and cruise conditions. The landing position is designed to give maximum lift while the take-off position is either sealed or slotted with respect to fixed leading edge of main element. This is done to ensure that a sealed slat minimizes drag better than a ventilated or slotted slat configuration as found in B777 liner. It can be noted the three-position slat is most favourable option for reducing the drag and maximizing lift compared to 2 position Kruger slat during take-off and landing situ- ations. The inboard wing of aircraft is usually equipped with a droop nose device during a takeoff or landing operation, since it offers good aerodynamic performance compared to sealed leading-edge slat. Figure 5(b) shows the variable camber Krueger leading-edge flap device. A simple Kruger flap with fixed camber is in shape of bull nose and designed to improve the landing performance. Also, a variable camber Kruger flap is equipped with a rotary track linkage in order to increase the maximum lift coefficient during landing. However, the linkage is more complex and expensive due to increased number of span wise panels used as stiffeners. A detailed study on high lift configurations for all commercial aircrafts is beyond the scope of present study and therefore restricted to only Boeing aircrafts. For most Boeing aircrafts, the trailingedge flaps the chord length in retracted position is typically between 20 to $35 \%$ of local chord while the flap overlap distance is $50 \%$ of flap chord. The maximum deflection of a single slotted flap is between $30^{\circ}$ and $40^{\circ}$ with a flap gap of about $2 \%$ of local chord. Fixed vane with a dropped hinge kinematics in a double-slotted flap can be deployed at angles between $40^{\circ}$ to $55^{\circ}$ with a gap equal to $1 \%$ local chord. Flap overlap in a double slotted flap with fully deployed position is $1 \%$ chord. Also, for double-slotted flaps aft of main element, the maximum main-flap deflection is between $30^{\circ}$ to $35^{\circ}$ with a first-flap gap of $2 \%$ chord. The aft flap can be deployed up to $63^{\circ}$ to $70^{\circ}$ relative to the wing-chord plane, with the second slot at $1 \%$ chord. Triple-slotted flaps are similar to main flaps with add on aft flap as shown in Figure 5(c). Generally, angles for the 


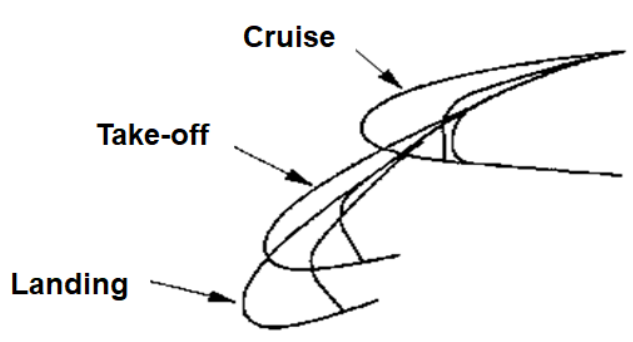

(a)

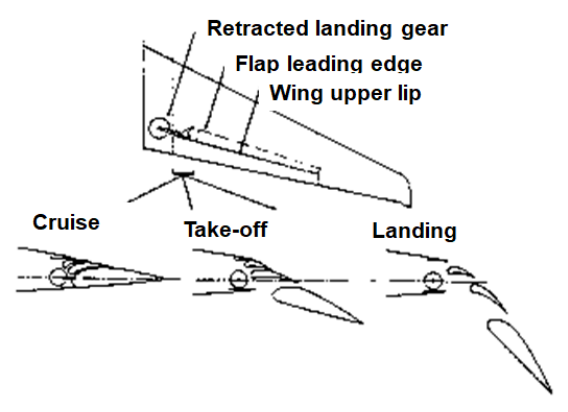

(c)

fixed vane and trailing edge flap are less than those used on double-slotted flaps. The aft-flap deflection on such systems varies between $65^{\circ}$ to $80^{\circ}$. Flap gaps are typically about $2 \%$ for the fixed vane and $1 \%$ of wing chord for the main and aft flaps. For best take-off, a higher glide ratio will increase gross weights using the maximum flap angle for single, double and triple-slotted flaps. The deflection angle also varies typically between $10^{\circ}$ and $20^{\circ}$ with only one slot. For low-gross-weight take-offs at high thrust-toweight ratios, the take-off flap and landing flap deflection angles are nearly identical.

\subsection{Noise radiation from high lift systems}

The high-lift system has an impact on airplane noise and airplane performance. Referring to the sound pressure level shown in Figure 6(a) multi-element aerofoils and airframe noise sources are major contributors. Airframe noise is due to formation of vortices and turbulence as result of separated flow regions and resonance induced in cavities. High-lift-system noise also impacts airplane glide ratio and hence power output from engine. In this context, the take-off noise amplitude is different from other sources because take-off engine power is not influenced by glide ratio. Take-off noise with reduced load on engine may affect the glide ratio since it varies with height of aircraft above ground and location from measuring microphone. Figure 6(b) shows the major noise sources on a landing aircraft equipped with two turbofan engines. It can be seen that flap and slat noise are important sources of noise in addition to noise from landing gear, nose wheel and engine sources. Usually slotted flaps are deployed only to a single-slotted configuration during take-off, and the differences in glide ratio for different high-lift configura-

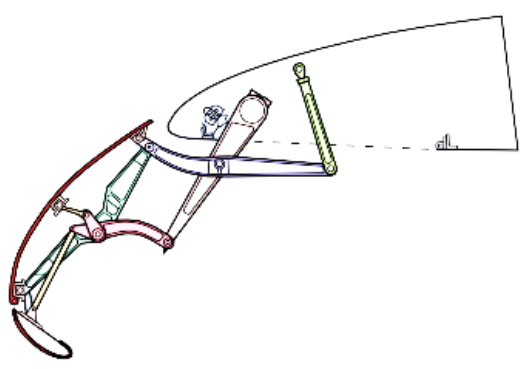

(b)

Figure 5. Position of high lift devices (a) 3 position leading edge slat operated by hinge mechanism during takeoff, landing and cruise modes of aircraft (Van Dam, 2002) (b) Variable camber Krueger flap found on commercial aircrafts (Heap \& Crowther, 2011) (c) Trailing edge flap position during takeoff, landing and cruise modes for DC-9 aircraft (Van Dam, 2002)

tions are therefore small. However, with increase in number of flaps the beneficial effect provided by Fowler motion is offset with increase in noise level during take-off or landing situations. The slotted configuration of leading and trailing-edge devices will impact the take-off glide ratio and subsequently the flow induced noise emanating from them.

As noted earlier, the glide ratio for landing configuration can be significantly influenced by the type of highlift system e.g. A Boeing 747-400 with low-aspect-ratio, triple-slotted flaps produces more vortices from outboard flap region and are bound to have a low glide ratio during landing than a Boeing 777 liner. Also, Krueger flaps with span wise gaps produce additional drag at low incidence angles during approach due to fairings involved in flap operation. Therefore, the engines with high power configuration produce more noise radiation and need to maintain the three-degree glide slope angle on final approach. In contrast, the Airbus A330/340 with continuous single-slotted flaps have a considerably high glide ratio and require a lower engine power in order to reduce noise radiation.

From Figure 6(a) the overall sound pressure level is high between the leading edge slat and main element but the peak sound level of $135 \mathrm{~dB}$ is seen in slat cove region. It must be noted that noise emission of vented leadingedge slat airfoil is high due to interaction of vortex-gust with surface of airfoil and found to be more compared to sealed slat case (Huang, 2019). At the trailing edge of slat the sound pressure level can reach up to $111 \mathrm{~dB}$. Research efforts are focused on reduction of noise associated with aircraft engines including airframe noise that has become an important contributor to the overall noise, especially 
during approach for landing when the aircraft engines are throttled down. Therefore, methods to reduce airframe noise involve advanced design of airframe, wing shape and materials which are essential for the development of quieter civil aircrafts. A leading-edge slat is commonly used as part of the high-lift devices deployed during landing and take-off, and unsteadiness associated with flow separation within the slat cove region is known to be one of the major components of the airframe noise. The thin shear layer emanating from the slat cusp and its subsequent reattachment upstream of the slat trailing edge produces broad-

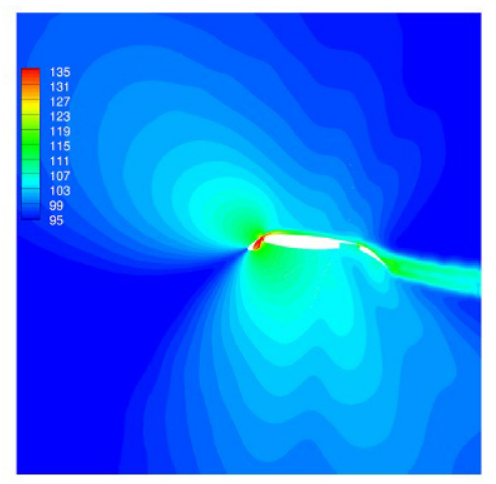

(a)

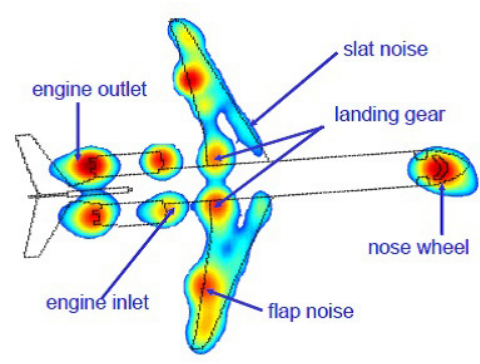

(b)

Figure 6. Illustration of noise radiation (a) from 30P-30N multi element airfoil computed using CFD method (Lockhard \& Choudhari, 2009) (b) measured from different sources on aircraft using microphone array method (Oerlemans, 2009) band noise. Finally, tonal noise produces narrow band peaks whose amplitudes are function of characteristic trailing edge geometry, angle of attack, Reynolds number, Strouhal number and state of the boundary layer flow (Nukala \& Maddula, 2020). Further, a tonal noise peak is quite often associated with vortex shedding behind a slat trailing edge with a finite thickness and produced due to stall separation inside the slat cove region. For a typical wind tunnel scale model, the frequency of trailing edge vortex shedding noise tends to be significantly higher than the dominant slat cove noise (Choudhari et al., 2014).

\subsection{Kinematic mechanisms on aircraft wings}

The types of kinematic mechanisms used commonly in a high lift system of aircraft in provided in Table 1, the type of motion necessary for the deployment or retraction of flaps hydraulically and a tradeoff reason for elimination.

Most Boeing aircrafts are equipped with double slotted flaps for both leading and trailing edge of wing. This usually tends to increase the complexity of flap track system. So, to reduce the system complexity of a ventilated leading-edge slat, an adaptive dropped hinge flap (ADHF) has been implemented in A350 XWB-900 aircraft (Struber, 2014). It eliminates fast actuation as well as the mechanical link between flap and spoiler thereby reducing the weight of the actuation subsystem in high lift systems. The presence of flaps requires track kinematics which enables large fowler motion i.e. increase in wing area and camber to allow for adjustments of flap angles optimally during take-off situation. Flaps with hinge kinematics are less complex and light weight however, it offsets the highlift configuration that can be aerodynamically optimized about a pivot point. Further, the pivot point needs to be positioned under wing in such a way to minimize cruise drag. Hinged flaps have ability to control the gap between the spoiler and the flap for laminar flows. To a large extent it depends on hinge position close to the trailing edge of wing which tends to constrain the flap motion. It leads to reduced wing area during take-off or landing manoeuvres. So, a desired flap motion on hinge enables to control the resulting large gap through the spoiler actuator and reduction in weight of the flap body and support structure. The complexity of kinematic mechanisms therefore affects

Table 1. Types of kinematic mechanisms in a high lift system

\begin{tabular}{|l|c|c|l|l|l|}
\hline \multirow{2}{*}{$\begin{array}{c}\text { Kinematic } \\
\text { mechanism }\end{array}$} & \multicolumn{2}{|c|}{ Number of slots } & \multirow{2}{*}{ Airliner example } & Type of motion & \multicolumn{1}{c|}{$\begin{array}{c}\text { Drawback } \\
\text { reason }\end{array}$} \\
\cline { 2 - 5 } $\begin{array}{l}\text { Simple or dropped } \\
\text { hinge }\end{array}$ & 1 & 1 & $\begin{array}{l}\text { Monoplane (ARV } \\
\text { Super 2) }\end{array}$ & Circular arc & Aerodynamic efficiency, wear \\
\hline Hooked track & 1 & 2.3 & B-757, 777 & Circular arc & $\begin{array}{l}\text { Reliability, wear, cost, aerodynamic } \\
\text { efficiency }\end{array}$ \\
\hline Link/ track & 1 & 2.3 & $\begin{array}{l}\text { A320/330/340 / } \\
\text { Boeing }\end{array}$ & $\begin{array}{l}\text { Straight \& } \\
\text { Circular arc }\end{array}$ & $\begin{array}{l}\text { Aerodynamic efficiency, depth of } \\
\text { fairing }\end{array}$ \\
\hline Four bar linkage & 1 & 1 & B-767 & Circular arc & Reliability, wear, cost \\
\hline
\end{tabular}


efficiency and reliability of high-lift systems by influencing aircraft weight and operation and maintenance cost, part count, and the number of hinges. In addition, a tradeoff between high aerodynamic performance and reliable structural design depends on the design methodology to increase efficiency at the expense of high direct cost.

Trailing-edge devices found on Boeing aircrafts include plain flaps to Fowler flaps with single, double, and even triple slots. In this regard, ailerons, elevators and rudders can be considered as plain flaps. The complexity of high-lift systems is high in Boeing 747 aircraft and houses a variable camber Krueger flap and triple-slotted, inboard and outboard trailing-edge flaps. This approach has resulted in high levels of lift with relatively simpler operation of kinematic devices in order to reduce acquisition and maintenance costs. Airbus wings are designed for the high flight Mach-number, Ma-0.85 that requires a higher sweep angle. The maximum quarter-chord sweep on the Mega-liner wing is $35.7^{\circ}$ while on the A340-300 wing it is only $29.8^{\circ}$ and on Douglas aircraft, DC- 9 it is $24.5^{\circ}$. It suggests that speed increase during cruise mode is possible by a wing with a high sweep angle but it tends to increase wing load. With increased wing loads, the maximum lift coefficient also rises at high flight Mach number. However, high sweep wing can lead to reduced lift for low speed manoeuvre and undesired pitch up behaviour of aircraft when the flow separation occurs on outboard region of wing. Hence a droop nose device able to rotate on a hinge line is preferred choice both on inboard and outboard of wing's leading edge. This favours maximum lift by delaying flow separation at higher incidence angles.
The dropped-hinge and four-bar mechanism on wing is usually equipped with a linear actuator or a rotary actuator. The link-track mechanisms are actuated by a rotary actuator while the hooked-track mechanisms are actuated by a linear actuator. The four-bar mechanism is designed for three stages and typically retracted for take-off and landing position. Compared to the dropped-hinge model, the support structure allows for additional joints aft of actuator attachment and part of the four-bar kinematics. As a result modifying support structure dimensions and actuator attachment position affects the flap motion. Further, the link-track mechanism offers more flexibility just like the four-bar linkage. A track is used to provide translation motion of flap while link determines the flap rotation. A hooked-track mechanism is similar to link track in which hooked track transmits the straight line motion of flap (Zaccai et al., 2016). As mentioned earlier, kinematic mechanisms in high lift systems use linear and rotary actuators which can be driven by servo or stepper motor. It can be seen from Figure 7(a) that torque actuators are necessary to connect gearboxes to allow the torque to be transmitted for desired flap motion. Figure 7(b) shows the flap deflection and its rotation about hinge. In some cases cardan coupling also allows connecting shafts to transmit the rotational motion. The torque taken by each mechanism is reduced by the losses from a gearbox. Therefore, it can be said that dropped hinge and hooked-track mechanism allows the flap deflection to reach maximum angle of $60^{\circ}$ and reduces the gap and overlap in the take-off configuration However, they are substantially lighter than the link-track and four-bar mechanism. Figure 7(c) illus-

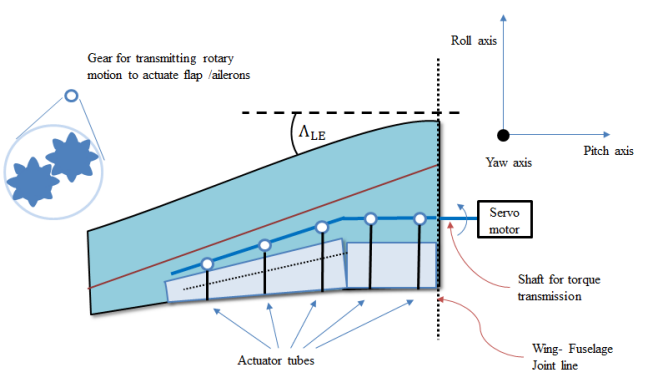

(a)

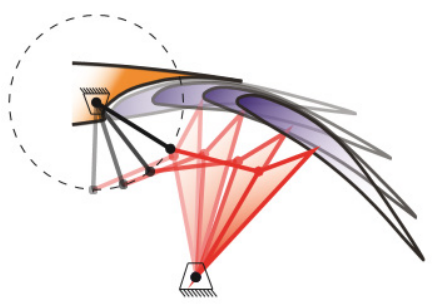

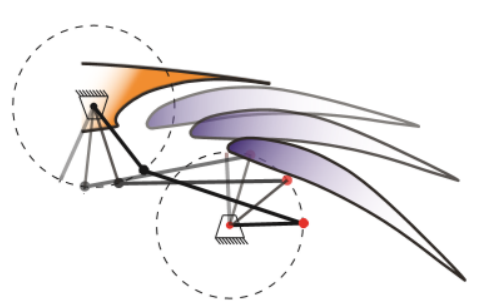

(c)

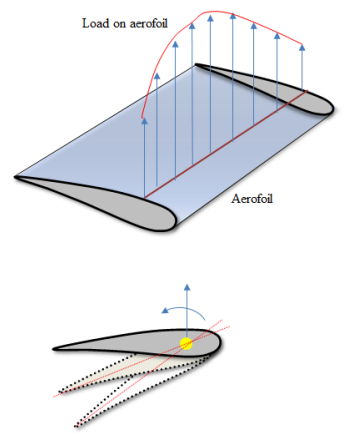

(b)

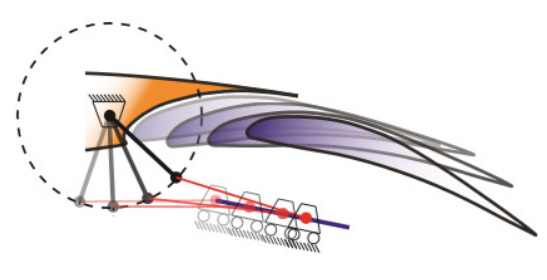

Figure 7. Illustration of (a) trailing edge flap actuation for a wing (b) aerodynamic loading action along quarter chord point of wing and flap motion about a hinge (adapted from Zaccai et al., 2016) (c) types of trailing edge flap kinematic mechanisms (Bertels, 2012) 
trates the dropped hinge, four bar linkage and link/track kinematic mechanisms with flap positions during actuation. Due to its low weight and low power consumption, the dropped-hinge mechanism has low overall system weight. Further, in terms of low part count and number of hinges the maintenance cost is also reduced significantly. Despite the link-track mechanism is a heavy mechanism, it offers higher aerodynamic performance compared to others and requires a relatively small actuation load. A detailed tradeoff analytic study on compensating the system weight and aerodynamic performance indicators such as, $\mathrm{C}_{\text {Lmax }}$, glide ratio, maximum take-off weight (payload) and direct cost is beyond the scope of present study.

\section{Case: surface pressure distribution of 30P-30N multi-element airfoil using $2 \mathrm{D}$ panel method}

As mentioned in introduction, CFD based computational methods involve setting up computational domain for given flow condition and mesh generation for a given geometry. Such method is accurate in the prediction of the aerodynamic performance characteristics and turbulent flow field by solving unsteady non-linear Navier-Stokes equations combined with turbulence models (Rahman et al., 2017; Jain \& Mohammad, 2018) The size of computational domain may vary with complexity of geometry, type of flow and boundary conditions which can be extended to near and far field. However, in panel methods, pressure distribution, velocity field and aerodynamic performance parameters such as lift, drag coefficients can be easily analyzed. Even though basic panel methods are suitable for characterizing potential flows it can be also be extended to viscous flows to predict results faster than CFD methods for simple and complex geometries (Haughton \& Carpenter, 2013).

In this work, $2 \mathrm{D}$ vortex panel method has been implemented for 30P-30N airfoil to evaluate pressure coefficient for a Reynolds number of 9 million at $16^{\circ}$ angle of attack. The free stream velocity corresponding to Re-9 million is $58 \mathrm{~m} / \mathrm{s}$. To validate our work, results from Dong and Zhang (2012) and Anderson et al. (1995) has been used. A snapshot of the computational panel method algorithm implemented using MATLAB routine is shown in Figure 8 and Figure 9(a) shows the basic geometry of 30P30N airfoil and Figure 9(b) illustrates the definition of deflection angles for flap, flap-gap and overlap distances at leading and trailing edge for $30 \mathrm{P} 30 \mathrm{~N}$ implemented for study. To compute pressure coefficient distribution, the geometric settings for $30 \mathrm{P} 30 \mathrm{~N}$ are assumed: slat angle $-30^{\circ}\left(\delta_{\mathrm{s}}\right.$ in Figure $9(\mathrm{~b})$ ), flap angle $-30^{\circ}\left(\delta_{\mathrm{f}}\right)$, slat gap $-2.9 \%$ main chord $\left(\mathrm{G}_{\mathrm{s}}\right)$, flap gap $-1.25 \%$ main chord $\left(\mathrm{F}_{\mathrm{s}}\right)$, slat overhang: $-2.5 \%$ main chord $\left(\mathrm{O}_{s}\right)$, flap overhang: $0.25 \%$ main chord $\left(\mathrm{O}_{\mathrm{f}}\right)$.

The length of panel is defined by node or end points while the source or vortex strengths for each panel is center at mid or control points along with unit tangential and normal vectors for describing the velocity components on the panel surface. Unknown source and vortex strengths $\sigma, \gamma$ on each panel are evaluated by solving the algebraic system of equations defined by influence coefficients. The solution of equations for a given geometry is achieved using influence coefficients which vary according to the flow configuration i.e. angle of attack and Reynolds number. Using the influence coefficients, the tangential velocity vector and pressure coefficient is obtained by integrating the source and vortex strengths for each panel. The tangential velocity vector field over the airfoil surface is calculated using the known values of influence coefficients on every panel i.e. Normal $\left(C_{n}\right)$ and tangential $\left(C_{t}\right)$ directions represented by matrix, $M$, source and vortex strength matrix $A$ and vertical velocity components matrix $B$, defined for each panel. The tangential velocity vector is used to determine the surface pressure coefficient along the chord length of the airfoil surface. It can be noted that panel method utilizes two essential boundary conditions viz. impermeable boundary condition in which the normal derivative of the velocity potential function is zero. The other is known as Kutta condition defined for the trailing edge panels. Kutta condition is valid for all airfoils with sharp trailing thickness for which flow over the trailing edge leaves smoothly (Dwivedi et al., 2019; Bhargava et al. 2017). Further, it is important to note that bound circulation surrounding the airfoil nullifies the trailing edge vortex strength downstream of wing in accordance with Kelvin-Helmholtz hypothesis. Hence, in panel method, a uniform circulation distribution at every control point of a panel is assumed for a given flow condition. For large positive angle of attack, aerofoil experiences the flow separation close to leading edge and forms leading edge vortex (LEV) within the laminar boundary layer (Alsahlan \& Rahulan, 2017). It must be noted that flow separation is caused due to the adverse pressure gradient in the boundary layer when the shear stress exceeds the velocity gradient close to wall or boundary (White, 2011; Bhargava et al., 2019a, Bhargava et al., 2019b). On the other hand, for any given angle of attack the flow separation occurs towards trailing edge and result as formation of trailing edge vortex (Bhargava et al., 2020). The trailing edge vortex impacts the maximum lift coefficient generated on aircraft wing along span wise direction. The strength of vortex causes downwash on the wing due to higher induced drag acting on the suction surface of wing than on the pressure surface (NASA Glenn Research Centre, 2019).

Therefore, most aircrafts are fitted with active flow control devices along the span as well as rakes or tip fences near the wing tip. The raked wing tip ensures starting vortex leaving the trailing edge causes the induced velocity to produce downwash at sufficient distance away from the wing tip rather than on the wing span region. A series of such continuous shed vortices away from wing span form a horse-shoe vortex structure behind the trailing edge. Further, the lift produced on wing is affected by angle of attack distribution along the wing span as well as the thickness to chord ratio of airfoil. A boundary layer is a region close to wall where the viscous forces are dominant. This region can be further divided into sub layers known as laminar 


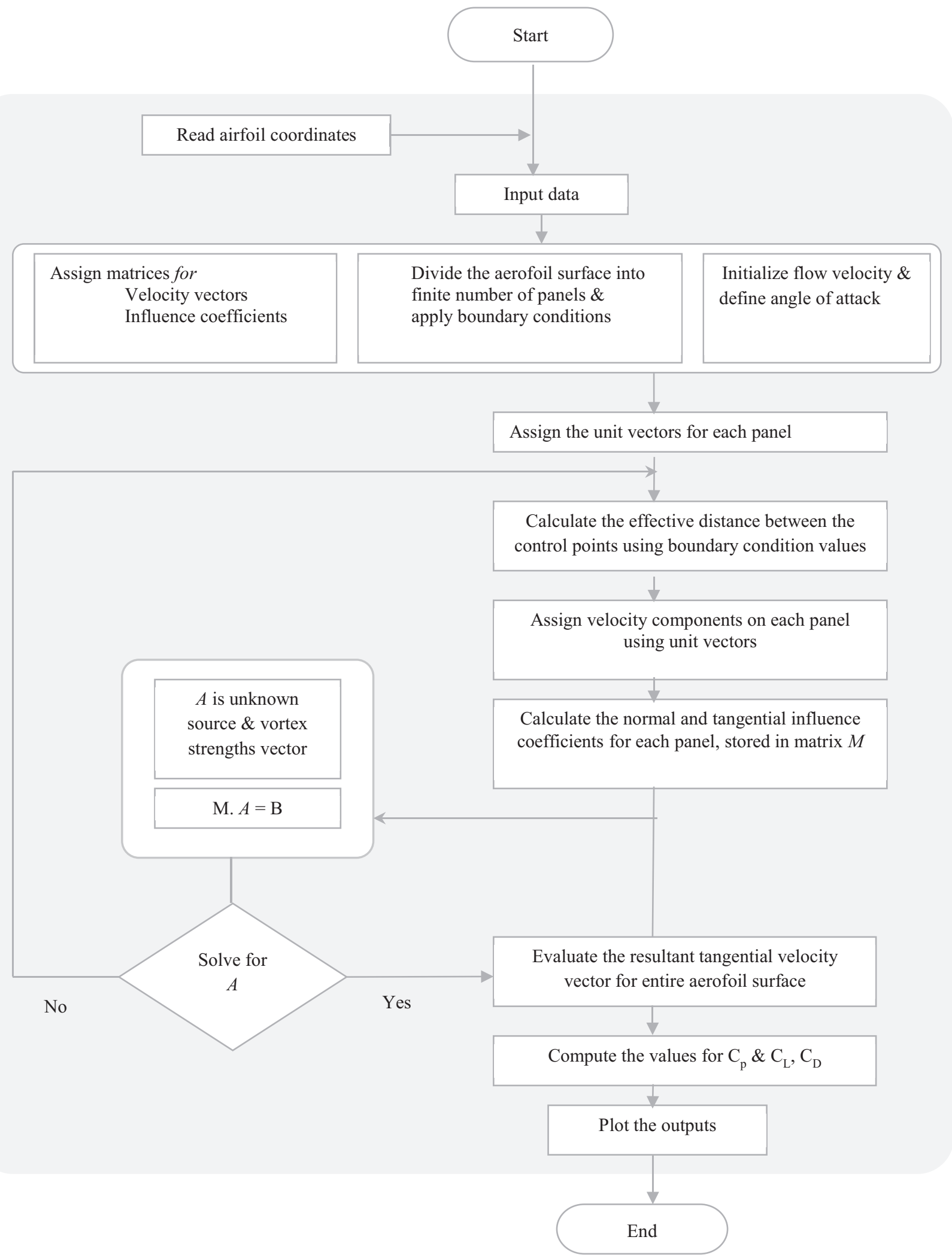

Figure 8. Computational routine of 2D panel method implemented in MATLAB (Dwivedi et al., 2019) 


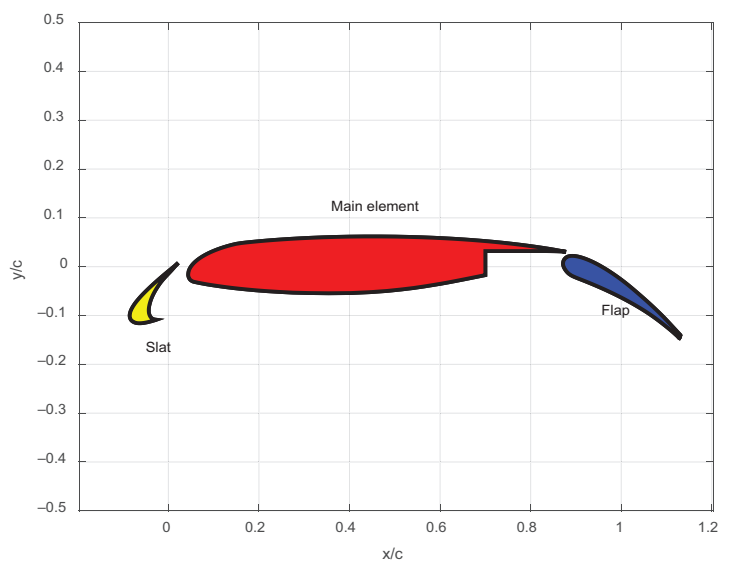

(a)

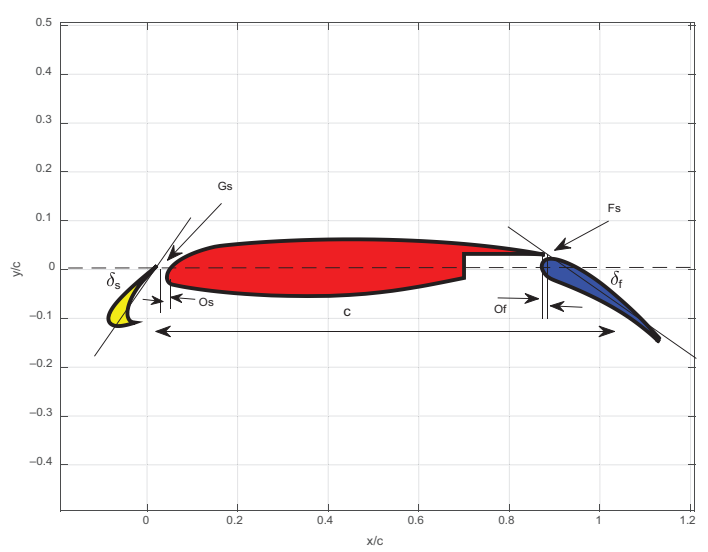

(b)

Figure 9. Illustration of 30P30N airfoil (a) Geometry (b) leading edge slat, trailing edge flap along with deflection angles with respect to chord line

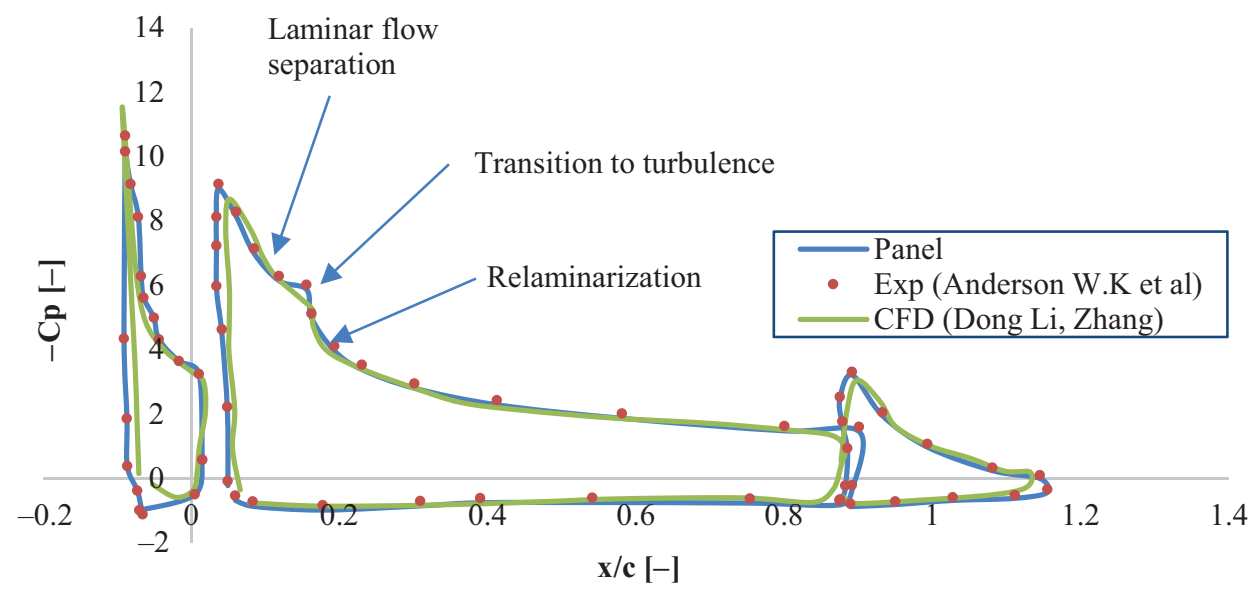

Figure 10. Comparison of pressure coefficient distribution computed using 2D panel method for 30P-30N airfoil with CFD results of Dong and Zhang (2012) and experiment results of Anderson et al. (1995) at $16^{\circ}$ angle of attack, Mach-0.2, Re-9 million

sub layer, log layer and outer turbulent layer in which the defects in velocity profile are dominant. For laminar attached flows, the shear stress is linearly proportional to the velocity gradient which suggests that pressure gradient remains in favorable state until a critical point known as inflexion is attained away from boundary. However for turbulent flows the velocity profile is governed by a power law for which turbulent kinetic energy dominates in a direction opposite to free stream flow. This results in an adverse pressure gradient which has sufficient energy to separate the flow from the wall and thereby forms a vortex of finite strength. So, the presence of slots or gaps in multi-element airfoil flows produces circulation and also responsible for producing lift on individual elements. It must be noted that direction of circulation on leading edge slat is opposite to that of trailing element. This causes a reduction of pressure recovery and suction peak of trailing element which leads to delayed flow separation and hence called slat effect. On the other hand circulation effect on leading edge of main element causes increased lift and aerodynamic loading with increased pressure recovery at trailing element. However, this pressure recovery is lowered due to high velocity on suction surface and when a new thin boundary layer starts to grow on trailing element that has potential to withstand adverse pressure gradient. This is known as damping effect since the pressure peaks on trailing elements are reduced in such a way that wakes of individual elements merge to form a confluent boundary layer which is thicker compared to ordinary boundary layer (Van Dam, 2002; Heap \& Crowther, 2011). These flow mechanisms on multielement airfoils tend to initiate transitions at a fixed or variable locations along chord and depend on the leading edge sweep angle, Reynolds number and surface roughness. In Figure 10 laminar flow separation is observed at $15 \% \mathrm{x} / \mathrm{c}$ followed by a transition to turbulence at $19 \% \mathrm{x} / \mathrm{c}$ location. This leads to reduction in the maximum lift at high flight Reynolds number. Howver, further downstream of chord, the relaminarization of flow occurs at $25 \% \mathrm{x} / \mathrm{c}$ due to strong horizontal acceleration or steeper favorable pressure gradient and compensates the loss of lift. The lift loss varies with flight 
Reynolds number, increased flap distance and wing sweep angle parameters. A flap and slat deflection angle of $30^{\circ}$ is used for computing the $\mathrm{C}_{\mathrm{p}}$ distribution and the results of the panel method are in better agreement wih CFD results from Dong and Zhang (2012) as well as with experiment values of Anderson et al. (1995) for high flight Reynolds number, Re-9 million.

\section{Summary and conclusions}

This paper discussed about high lift devices on modern aircraft and its importance on flight performance of aircraft. The following conclusions can be made:

1. The presence of high lift devices either at inboard or outboard regions along aircraft wingspan improves the aerodynamic and flight performance significantly. Fowler and Krueger flaps show a remarkable increase in maximum lift coefficient up to $100 \%$ as the no of slots on wing is increased. The maximum lift coefficient has direct impact on take-off, landing performances of aircraft.

2. The shape of wing tips for commercial aircrafts show significant influence on the span wise wing loading during cruise mode. For reducing the downwash on wing span, the wing tips are swept back and out of plane direction to reduce vortex drag on wing and fuel consumption on long range flights. The aspect ratio of wing is key design feature to improve the flight Mach number for long range flights. High aspect ratio wings show reduced skin friction drag but dramatically increase pressure drag and contribute to the fuel efficiency of aircrafts.

3. Ascent or descent rate during take-off or landing stages are function of thrust to weight ratio, aerodynamic performance and maximum lift coefficient and vary with no of slots deployable on aircraft wing. The total drag on aircraft wing during operation can be obtained using the vector addition of no of flaps, slats; landing gear, pressure drag and wave drag components.

4. The kinematic mechanisms play major role to control the motion of flaps and slats on aircraft wings. Four bar linkage mechanism with a circular arc motion is most suited in terms of aerodynamic efficiency of an aircraft wing while the simple or dropped hinge mechanism is cost efficient due to its low part count and simplicity of operation.

\section{Acknowledgements}

Authors would like to thank the reviewers and editors who provided useful comments in improving the quality of the work. The authors would also like to thank Prof. Vijaya Srivastava, TEFL University, Lucknow campus for her valuable comments on the manuscript and English language proof reading.

\section{Funding}

There is no funding for this project.

\section{Author contributions}

Swamy Naidu N. V. - Conceptualization, review and editing, Satya Prasad Maddula - Literature survey, code development and drafting, Vasishta Bhargava - Literature survey, methodology, validation and drafting.

\section{Disclosure statement}

Authors declare no conflict of interest.

\section{References}

Anderson, W. K., Bonhaus, D. L., McGhee, R., \& Walker, B. (1995). Navier-Stokes computations and experimental comparisons for multi-element aerofoil configurations. Journal of Aircraft, 32(6), 1246-1253.

Alsahlan, A. A., \& Rahulan, T. (2017). Aerofoil design for unmanned high altitude aft-swept flying wings. Journal of Aerospace Technology and Management, 9(3), 335.

https://doi.org/10.5028/jatm.v9i3.838

Bertels, F. G. A. (2012). Design framework for flap system kinematics; a knowledge-based engineering application (Master thesis). Delft University of Technology.

Bhargava, V., Dwivedi, Y. D., \& Rao, P. M. V. (2017). Analysis of multi-element airfoil configurations: a numerical approach. MOJ Applied Bionics and Biomechanics, 1(2), 83-88. https://doi.org/10.15406/mojabb.2017.01.00012

Bhargava, V., Samala, R., \& Anumula, C. (2019a). Prediction of broadband noise from symmetric and cambered airfoils. $I N$ CAS Bulletin, 11(1), 39-51. https://doi.org/10.13111/2066-8201.2019.11.1.3

Bhargava, V., Rahul, S., \& Maddula, S. P. (2019b, June). Empirical method of determining vortex induced aerodynamic noise from wind turbine blades: A computational approach. Paper presented at the $48^{\text {th }}$ International congress and exhibition on noise control engineering. Madrid, Spain.

https://doi.org/10.3849/aimt.01295

Bhargava, V., Kasuba, S., Maddula, S. M., Jagadish, D., Khan, Md. A., Padhy, C. P., Chinta, H. P., Chekuri, C. S. V., \& Dwivedi, Y. D. (2020). A case study of wind turbine loads and performance using steady state analysis of BEM. International Journal of Sustainable Energy. https://doi.org/10.1080/14786451.2020.1787411

Catalano, F. M., Ceron, E. D., \& Greco, P. C. (2012). Trailing edge treatment to enhance high lift system performance. 28th International Congress of the Aeronautical Sciences (ICAS). Turkey.

Chernyshev, S. L., Iyapunov, V. S., \& Wolkov, A. V. (2019). Modern problems of aircraft aerodynamics. Advances in Aerodynamics, 1, 7. https://doi.org/10.1186/s42774-019-0007-6

Choudhari, M., Murayama, M., Nakakita, K., Yamamoto, K., Hiroki, U., \& Ito, Y. (2014). Experimental study of slat noise from $30 \mathrm{P} 30 \mathrm{~N}$ three element high lift airfoil in JAXA hard wall low speed wind tunnel. 20 $0^{\text {th }}$ AIAA/CEAS Aero-acoustics Conference. Atlanta, GA. https://doi.org/10.2514/6.2014-2080

Catalano, F. M., Ceron, E. D., \& Greco, P. C. (2012). Trailing edge treatment to enhance high lift system performance. 28th International Congress of the Aeronautical Sciences (ICAS). Brisbane, Australia. 
Deng, N., Qu, Q., \& Agarwal, R. K. (2018). Numerical study of aerodynamics of rectangular multi-element wing in ground effect. Applied aerodynamics conference. Atlanta, Georgia. https://doi.org/10.2514/6.2018-4115

Dong, L., \& Zhang, Z. (2012, 23-28 September). Numerical investigation of flow over multi element airfoils with lift enhancing tabs. $28^{\text {th }}$ international Congress of the Aeronautical Sciences. Brisbane, Australia.

Dwivedi, Y. D., Bhargava, V., Rao, P. M. V., \& Donepudi, J. (2019). Aerodynamic performance of micro-aerial wing structures at low Reynolds number. INCAS Bulletin, 11(1), 107-120. https://doi.org/10.13111/2066-8201.2019.11.1.8

FAA. (2019). Standard airworthiness certification regulations part 25: airworthiness standards: transport category airplane. https://www.faa.gov/aircraft/

Haroon, K. (2011). The airline pilots forum and resource, principles of flight. https://www.theairlinepilots.com/forum

Haughton, E., \& Carpenter, S. (2013). Aerodynamics for engineering students (6th ed.). Elsevier publishers.

Heap, H. \& Crowther, B. (2011). A review of current leading edge device technology and of options for innovation based on flow control. University of Manchester, UK.

Hess, J. L. \& Smith, A. M. (1967). Calculation of potential flow about arbitrary bodies. Progress in Aerospace Sciences, 8, 1-138. https://doi.org/10.1016/0376-0421(67)90003-6

Huang, X. (2019). A theoretical study of serrated leading edges in aerofoil and vortical gust interaction noise. Advances in Aerodynamics, 1, 6. https://doi.org/10.1186/s42774-019-0010-y

Husse, O. (2006). Best practices for fuel economy. ICAO Operational Measures Workshop. Montreal.

IATA. (2019). Jet fuel price monitor. IATA publication. https:// www.iata.org/en/publications/economics/fuel-monitor/

Jain, S., Sitaram, N., \& Krishnaswamy, S. (2015). Computational investigations on the effects of Gurney flap on airfoil aerodynamics. Hindawi Publishing Corporation.

https://doi.org/10.1155/2015/402358

Jawahar, H. K., Azarpyevand, M., \& Carlos, R. S. (2017). Experimental investigation of flow around three element high lift airfoil with Morphing Fillers. 23rd AIAA/CEAS Aero-Acoustics Conference. Denver, Colorado. https://doi.org/10.2514/6.2017-3364

Jain, R., \& Mohammad, U. (2018). CFD approach of Joukowski airfoil $(\mathrm{T}=12 \%)$, comparison of its aerodynamic performance with NACA airfoils using k- $\varepsilon$ turbulence model with 3 million Reynolds number. International Research Journal of Engineering and Technology, 5(10), 1414-1418.

Liebeck, R. H. (1978). Design of subsonic aerofoils for High lift. Journal of Aircraft, 15(9). https://doi.org/10.2514/3.58406

Lockhard, P. D., \& Choudhari, M. (2010). The effect of cross flow on slat noise. $16^{\text {th }}$ AIAA/CEAS Aero-acoustics Conference. Stockholm, Sweden. https://doi.org/10.2514/6.2010-3835

Lockhard, D., \& Choudhari, M. (2009). Noise radiation from a leading slat. $15^{\text {th }}$ AIAA/CEAS aero-acoustics conference. Miami, Florida, US. https://doi.org/10.2514/6.2009-3101
Nukala, V., \& Maddula, S. P (2020). Influence of rotor solidity on trailing edge noise from wind turbine blades. Advances in Aerodynamics, 2(15). https://doi.org/10.1186/s42774-020-00036-9

NASA Glenn Research Centre. (2019). Shed Vortex. Aerodynamics Index - Beginners Guide. https://www.grc.nasa.gov/ www/k-12/airplane/

Oerlemans, S. (2009). Detection of aeroacoustic sound sources on aircraft and wind turbines (Doctoral thesis). University of Twente, Enschede. ISBN 978-90-806343-9-8.

Pascioni, K. A., Cattafesta, L. N., \& Choudhari, M. (2014). An experimental investigation of the $30 \mathrm{P}-30 \mathrm{~N}$ multi-element high lift airfoil. 20 th AIAA/CEAS Aero-acoustics Conference. Atlanta, Georgia. https://doi.org/10.2514/6.2014-3062

Rahman, A. H. A., Mohd, N. A. R. N., Lazim, T. M., Mansor, Sh. (2017). Aerodynamics of harmonically oscillating aerofoil at low Reynolds number. Journal of Aerospace Technology and Management, 9(1), 83-90.

https://doi.org/10.5028/jatm.v9i1.610

Reckzeh, D. (2008). Aerodynamic design of theA400M high lift system. $26^{\text {th }}$ International congress of the aeronautical sciences. Anchorage, Alaska, Canada.

Reckzeh, D. (2004). Aerodynamic design of airbus high-lift wings in a multidisciplinary environment. European Congress on computational methods in applied sciences and engineering. ECCOMAS.

Rudolph, C. K. P. (1996). High lift systems on commercial subsonic airliners. NASA Contractor Report 4746 -A463474LD (LAS).

Sankar, L. N., Liu, Y., Englar, R. J., \& Ahuja, K. K. (2001). Numerical simulations of steady and unsteady aerodynamic characteristics of a circulation control wing airfoil. American Institute of Aeronautics \& Astronautics. https://doi.org/10.2514/6.2001-704

Struber, H. (2014). The aerodynamic design of the A350 XWB -900 high lift system. $29^{\text {th }}$ Congress of International Council of the Aeronautical Sciences. St Petersburg, Russia. https://doi.org/10.1016/S1270-9638(02)00002-0

Van Dam, C. P. (2002). The aerodynamic design of multielement high lift systems for transport airplanes. Progress in Aerospace Sciences, 38(2), 101-144. https://doi.org/10.1016/S0376-0421(02)00002-7

White, F. M. (2011). Fluid mechanics (7th Ed.). McGraw Hill Publishers.

Xuguo, Q., Peiqing, L., \& Qiulin, Q. (2009). Aerodynamics of a multi-element airfoil near ground. Journal of Tsinghua Science and Technology, 14(S2), 94-99. ISSN 1007-0214.

Zaccai, D., \& Bertels, F. \& Vos, R. (2016). Design methodology for trailing edge high lift mechanisms. $5^{\text {th }}$ CEAS Air \& Space Conference. Netherlands. https://doi.org/10.1007/s13272-016-0202-7

Zhang, X., Qu, Q., \& Agarwal, R. K. (2017). Computations of flow fields of an aerofoil and a wing with Gurney flap in ground effect. AIAA Aerospace Sciences Meeting. Kissimmee, Florida. https://doi.org/10.2514/6.2017-4466 